www.jmscr.igmpublication.org

Index Copernicus Value: 79.54

ISSN (e)-2347-176x ISSN (p) 2455-0450

crossrefDOI: https://dx.doi.org/10.18535/jmscr/v7i3.80

\title{
Recurrent Foetal Loss- A Cross Sectional Study
}

\author{
Authors \\ Dr Deepankshu Shekhar Mandal ${ }^{1}$, Dr Subhankar Kumar ${ }^{1 *}$, Dr Somi Dey Sarkar ${ }^{2}$ \\ ${ }^{1}$ Associate Professor, Physiology, IPGME \& R, Kolkata, WB \\ ${ }^{2}$ Commandant/CMO (SG), Department of Pathology, CAPFs' Composite Hosp', BSF, Siliguri, WB \\ *Corresponding Author \\ Dr Subhankar Kumar
}

Mob: 9830525033, Email: wphysiology@ gmail.com

\begin{abstract}
Recurrent pregnancy loss affects between 1 in 300 couple aspiring for a baby. Potential causes remains unexplained in even up to half of the cases. The objective of the study is to determine if the free T4 \& TSH level, USG of pelvic organs, Anti phopholipid antibody, thrombophilia, VDRL, TORCH, other infections, Rh incompatibility, diabetes, deficiency of coagulation inhibitors can be implicated in the increased incidence of fetal loss.
\end{abstract}

Keywords: Recurrent pregnancy loss, Anti phopholipid antibody.

\section{Introduction}

The problem burden: Spontaneous Foetal loss is the most common complication of pregnancy. Approximately $70 \%$ of human conceptions fail to achieve viability and $50 \%$ are lost before the first missed menstrual period ${ }^{[1]}$. Many of these very early foetal losses are recognized only by using sensitive assays for human chorionic gonatotrophin (incidence up-to $31 \%$ !). Of pregnancies that are clinically recognized, loss occurs in $15 \%$ before 20 weeks of gestation ${ }^{[2]}$. $70 \%$ of all first twelve weeks spontaneous abortions are due to chromosomal anomalies. But after twelve weeks, cervical incompetence and hematological disorders are common causes of recurrent pregnancy loss ${ }^{[3]}$. The antiphospholipid syndrome is the most common cause of acquired thrombophilia. ${ }^{[4]}$ It is associated with complications that span all trimesters of pregnancy which include recurrent miscarriage, severe pre eclampsia, intrauterine growth restriction and placenta abruptio ${ }^{[5,6,7]}$. Recurrent clinically detected pregnancy loss affects between 1 in 300 to 1 in 100 couples $^{[8]}$. Parental chromosomal abnormalities and thrombotic complications of the APAS (antiphospholipid antibody syndrome, with incidence@ 20\% in all Auto-immune disorder including APAS), are the only undisputed causes of recurrent abortions. However these abnormalities account for less than $10 \%$ to $15 \%$ of recurrent pregnancy loss. Other established causes are anatomic abnormalities $(12 \%-16 \%)$, endocrine problems $(17 \%-20 \%)$, infections $(0.5 \%-5 \%)$ and immunologic factors including those associated with APAS (20\% $50 \%$ ). Other miscellaneous causes have been 
implicated and account for approximately $10 \%$ of cases. Even after thorough evaluation the potential cause remains unexplained in about one third to half of the cases ${ }^{[8,9]}$. In this Tertiary Care Centre in West Bengal, India which caters to such patient in the day care scenario with the physically and emotionally crippling affliction of recurrent pregnancy loss, ladies were recruited with a history of two or more first trimester pregnancy losses or one unexplained fetal loss during second or third trimester for this study. These ladies were evaluated for free T4 \& TSH level, USG of pelvic organs and antigenic protein assays were performed to ascertain the correlation between unexplained recurrent fetal loss and parameters like endocrine dysfunction, detection of anatomic abnormality and Antiphospholipid antibody.

Parameters to assess Thrombophilia, infections and other laboratory studies like TORCH, ABO and $\mathrm{Rh}$ grouping \& typing, blood glucose and VDRL were also investigated and recorded.

\section{Material and Method}

31 Females of reproductive age group, (18 to 45 years) who voluntarily participated in this cross sectional study, with no other clinically detectable abnormality and a complaint of two or more first trimester pregnancy losses or one unexplained fetal loss during second or third trimester were subjected to tests like USG of pelvic organs, APLA (antiphospholipid Antibody), VDRL, TORCH (Toxoplasma Rubella Cytomegalovirus Herpes simplex), ABO and Rh grouping \& typing, blood glucose, Protein C, Protein S, Antithrombin III and free T4 \& TSH level. The tabulated test result were analyzed using appropriate statistical tools.

\section{Result and Analysis}

In all 31 subjects with history of unexplained recurrent pregnancy loss, between the ages of 21 to 33 years, USG of pelvic organs were found to be within normal limits. APLA reactivity was found to be negative in all subjects. VDRL \& TORCH were non reactive, only 1 subject had Rh negative blood and Random blood glucose were within range for all. Free T4 \& TSH level were found to be within normal limits for all. The amount of pregnancy loss was highly significantly associated with diminished functional activity of protein $\mathrm{S}$ levels in cases $(\mathrm{p}=0.003)$ but level of reduced functional activity of protein $\mathrm{C}$ deficiency was not significantly associated with the quanta of pregnancy loss in the same group of patients ( $\mathrm{p}=$ 0.359). It was also evident that no significant association of number of pregnancy loss was detected with elevated functional activity of antithrombin III levels in cases $(p=0.485)$.

\section{Conclusion}

Antithrombin III deficiency as a risk factor for recurrent foetal loss could not be reproduced in the present study where antithrombin III deficiency $(\mathrm{r}=-0.184 ; \mathrm{p}=0.322)$ is not a significant factor. The present study could not measure other anticoagulation related parameters like activated protein $C$ resistance associated with mutations in factor $\mathrm{V}$ Leiden mutation, mutation in prothrombin gene promoter (G20210A) and thermolabile mutation for methylenetetrahydrofolate reductase $\mathrm{C}_{677 \mathrm{~T}^{[10]}}$. Also of biopsy analysis from the reproductive tract of the cases along with measurement of local cytokines (collected at the time of foetal loss) would have been a valuable addition to the data pool.

Funding: No funding sources

Conflict of interest: None declared

Ethical approval: Obtained

\section{References}

1. Edmonds DK, Lindsay KI, Miller JF. Early embryonic mortality in women. Fertil Steril 1982;38:447-453.

2. Wilcox AJ, Weinberg CR, O'Connor JF, et al. Incidence of early loss of pregnancy. $\mathrm{N}$ Engl J Med 1988;319:189-194.

3. Hatasaka HH. Recurrent miscarriage: Epidemiologic factors, definitions and 
incidence. Clin Obstet Gynecol 1994; 37:625-34.

4. Wang J, Trudinger BJ, Duarte N, Wilcken DE, LiWang $X$. Elevated circulating homocysteine levels in placental vascular disease and associated pre-eclampsia. Br J Obstet Gynaecol 2000;107:935-8.

5. Rai R, Regan L. Antiphospholipid syndrome and pregnancy loss. Hosp Med 1998;59:637-9.

6. Backos M, Rai R, Baxter N, Chilcott IT, Cohen H, Regan L. Pregnancy complications in women with recurrent miscarriages associated with antiphospholipid antibodies treated with low dose aspirin and heparin. Br J Obstet Gynaecol 1999; 106:102-7.

7. Kupferminc MJ, Eldor A, Steinman N, Many A, Bar-Am A, Jaffa A, et al. Increased frequency of genetic thrombophilia in women with complications of pregnancy. N Engl J Med 1999;340:9-13.

8. Alberman E. The epidemiology of repeated abortion. In: Beard RW, Sharp F, eds. Early pregnancy loss: mechanisms and treatment. New York, NY: SpringerVerlag, 1988:9-17.

9. Greer IA. Thrombophilia: implications for pregnancy outcome. Thromb Res 2003;109:73-81.

10. Lindqvist PG, Svensson PJ, Dahlback B, et al. Factor V Q506 mutation (activated protein $\mathrm{C}$ resistance) associated with reduced intrapartum blood loss a possible evolutionary selection mechanism. Thromb Haemost 1998;79:69-73. 